\title{
De rol van religie in orgaandonatie
}

\author{
Hans Schmeets \& Floris Peters
}

\begin{abstract}
Dit artikel onderzoekt de relatie tussen religiositeit en donorregistratie, met behulp van unieke register- en enquêtegegevens onder bijna 400.000 personen. Eén op de vier mensen van de Nederlandse bevolking van 12 jaar of ouder is geregistreerd als orgaandonor. Onkerkelijken geven vaker toestemming om hun organen te gebruiken dan mensen die zeggen dat ze tot een kerkelijke gezindte of levensbeschouwelijke groepering behoren. Vooral zijn er weinig orgaandonoren onder de groep die zeer frequent een religieuze dienst bijwoont. Verder is er een verschil tussen de denominaties. Rooms-katholieken zijn vaker geregistreerde orgaandonoren dan protestanten, en dat is vooral het geval onder de oudere generatie. Moslims hebben veruit het laagste aandeel orgaandonoren.
\end{abstract}

\section{Inleiding}

Religie speelt ook in de moderne samenleving een belangrijke rol. Zo is religie een onderscheidende factor bij talrijke sociale aspecten, zoals gezondheid en leefstijlen, ${ }^{1}$ criminaliteit $^{2}$ en ervaren geluk. ${ }^{3}$ Ook wordt de religieuze binding dikwijls in verband gebracht met sociaal kapitaal in de vorm van vertrouwen hebben in en het meedoen met de samenleving, zoals hulp verlenen aan anderen, de inzet als vrijwilliger, het geven aan goede doelen en het stemmen bij verkiezingen. ${ }^{4}$ Veelal komt naar voren dat religieuze personen meer sociaal kapitaal hebben dan nietreligieuzen. In het verlengde daarvan kan worden verwacht dat het aandeel donoren onder religieuzen relatief hoog is. De bereidheid om organen en weefsel af te staan, kan worden gezien als een altruïstische uiting van de wil om bij te dragen of te geven aan de Nederlandse maatschappij. ${ }^{5}$ Het afstaan van organen duidt op betrokkenheid met de medemens en is een unieke vorm van geefgedrag, aangezien het een gebeurtenis is die na de dood plaatsvindt. Het afstaan van organen is te vergelijken met het geven aan goede doelen dat pas na de dood wordt geëffec-

1 J.-W. Bruggink \& M. van Herten, 'Religie, gezondheid en leefstijl', in: H. Schmeets \& R. van der Bie (red.), Religie aan het begin van de 21ste eeuw, Den Haag/Heerlen 2009, p. 53-64.

2 T. Traag, O. Marie \& R. van der Velden, 'Risicofactoren voor voortijdig schoolverlaten en jeugdcriminaliteit', Bevolkingstrends 2010, 2, p. 55-60.

3 M. Coumans, 'Meer religie, meer welzijn?', Bevolkingstrends 2014, juli.

4 R. Bekkers \& T. Schuyt, 'And who is your neighbor? Explaining denominational differences in charile giving and volunteering in the Netherlands', Review of Religious Research 2010, 1, p. 74-96; J. de Hart, Geloven binnen en buiten verband, Den Haag 2014; R.D. Putnam \& D.E. Campbell, American Grace. How Religion Divides and Unites Us, New York 2014; H. Schmeets, 'Religieuze betrokkenheid en sociale samenhang', in: H. Schmeets (red.), Sociale samenhang. Wat ons bindt en verdeelt, Den Haag/Heerlen/Bonaire 2015, p. 169-181.

5 R. Bekkers, 'Traditional and Health-Related Philanthropy: The Role of Resources and personality', Social Psychology Quarterly 2006, 4, p. 349-366. 
tueerd. Hoewel de motieven van dit 'geefgedrag' niet bekend zijn, is het wel een indicatie voor de band die iemand met de samenleving heeft. Het is immers niet mogelijk organen louter beschikbaar te stellen voor bepaalde personen of groepen, waardoor donorschap altijd een uiting van algemene generositeit is. De veronderstelling hierbij is dan ook dat hoe meer personen bereid zijn om hun organen ter beschikking te stellen aan (onbekende) anderen, hoe groter de band tussen mensen en daarmee de sociale cohesie in de samenleving is. Vandaar de verwachting dat een sterkere religieuze verbondenheid gepaard gaat met een grotere kans om de organen ter beschikking te willen stellen. ${ }^{6}$ Maar religie zal tevens een rol spelen bij de visie op leven en dood, en dat maakt de duiding van het effect van religie op orgaandonatie tot lastige materie.

Onderzoek naar de invloed van religie op orgaandonatie is vooral interessant voor een land als Nederland, omdat het religieuze landschap in Nederland als gevolg van de secularisatie ${ }^{7}$ en sterkere religieuze diversiteit ${ }^{8}$ drastisch is veranderd. Honderd jaar geleden behoorde meer dan 95\% van de Nederlandse bevolking tot een christelijke denominatie, en ging bijna iedereen in Nederland regelmatig naar de kerk om de diensten van de Nederlandse-hervormde, de gereformeerde of de katholieke kerk bij te wonen. Sindsdien is het deel dat niet behoort tot een kerk of religieuze groep gegroeid van 5\% in 1909 naar 49\% in 2014. ${ }^{9}$ In 2014 was één op de vier Nederlanders rooms-katholiek, en één op de zes protestant. Van de protestanten gaf $7 \%$ aan Nederlands-hervormd te zijn, $3 \%$ gereformeerd, en $6 \%$ gaf aan te behoren tot de Protestantse Kerk in Nederland (PKN). De relatief kleine groep PKN'ers is opmerkelijk tegen de achtergrond van het samengaan in 2004 van de meeste gereformeerde en hervormde kerken. ${ }^{10}$ Blijkbaar vindt nog steeds een relatief grote groep protestanten, hoewel ze formeel behoren tot de PKN, dat ze gereformeerd of Nederlands-hervormd zijn en identificeren ze zich niet met de PKN.

Daarnaast was $5 \%$ moslim, en $6 \%$ gaf aan tot een 'andere' denominatie of religieuze groep te behoren. Het regelmatige bezoek - minstens één keer per maand - van religieuze diensten is onder de volwassen Nederlandse bevolking afgenomen in de afgelopen vijftig jaar: van 37 naar 16\%. Verder is er een sterke variatie in kerkbezoek tussen de denominaties. Protestanten vertonen een veel hoger

6 M.D. Nijkampa e.a., 'To be(come) or not to be(come) an organ donor, that's the question: A meta-analysis of determinants and intervention studies', Health Psychology Review 2008, 2, p. 20-40; L.M. Range \& G.F. Brazda, 'How Organ Donors are Different from Non-donors: Responsibility, Barriers, and Religious Involvement', Journal of Religious Health 2015, p. 2286-2291.

7 R. Stark \& L.R. Iannaccone, 'A supply-side reinterpretation of the secularization of Europe', Journal for the Scientific Study of Religion 1994, 3, p. 230-252 H.F. te Grotenhuis \& P. Scheepers, 'Churches in Dutch: Causes of religious disaffiliation in the Netherlands, 1937-1995', Journal for the Scientific Study of Religion 2001, 4, p. 591-606.

8 O. Aarts, Religious Diversity and Religious Involvement: A Study of Religious Markets in Western Societies at the End of the Twentieth Century (diss. Nijmegen RU), Nijmegen 2010.

9 H. Schmeets \& C. van Mensvoort 'Religieuze betrokkenheid van bevolkingsgroepen', Bevolkingstrends 2015, 11, p. 1-13. Alle navolgende gegevens in deze alinea zijn gebaseerd op dit artikel.

10 H. Schmeets, 'Het belang van de religieuze binding in sociale statistieken', Tijdschrift voor Religie, Recht en Beleid 2010, 3, p. 29-41. 
kerkbezoek dan rooms-katholieken: twee op de drie gereformeerden, de helft van de PKN'ers, en drie op de tien Nederlands-hervormden ging regelmatig naar een kerkdienst, terwijl een vrij klein aandeel van $18 \%$ rooms-katholieken een dienst op een regelmatige basis bijwoonde. Moslims nemen een gemiddelde positie in: vier op de tien moslims bezocht ten minste één keer per maand een gebedsdienst in een moskee.

Nederland kampt met een tekort aan orgaandonoren, ${ }^{11}$ en het recente initiatiefvoorstel van D66 beoogt daar verandering in te brengen door iedereen die zich niet heeft laten registreren automatisch orgaandonor te maken. Op 31 december 2015 stonden 984 transplantabele personen op een donorwachtlijst. Elk jaar is er een Donorweek, meestal in oktober, waarin veel vrijwilligers proberen mensen over te halen om zich te registreren. Sinds 2014 beschikt het Centraal Bureau voor de Statistiek (CBS) over gegevens omtrent donorregistratie in Nederland. De data zijn afkomstig van het Donorregister, waarin sinds 1998 uitvoering wordt gegeven aan de Wet op de orgaandonatie (Wod). In deze wet is geregeld dat iedereen van 12 jaar of ouder die is ingeschreven bij een Nederlandse gemeente zijn of haar keuze op het gebied van orgaan- en weefseldonatie kan laten registreren. De dataset bevat individuele informatie over de Nederlandse bevolking van 12 jaar en ouder ( $n=14.610 .125$ ) en heeft betrekking op het jaar 2014. Deze dataset is gekoppeld aan gegevens uit de Enquête Beroepsbevolking (EBB) van 2010-2014. Registratie in het Donorregister kent de volgende keuzemogelijkheden: (1) 'Ik stel mijn organen en weefsels na mijn overlijden wel beschikbaar voor transplantatie', (2) 'Ik stel mijn organen en weefsels na mijn overlijden niet beschikbaar voor transplantatie', (3) 'Mijn partner of familie beslist na mijn overlijden of mijn organen en weefsels beschikbaar zijn voor donatie', en (4) 'Ik laat de beslissing of mijn organen en weefsels beschikbaar zijn voor transplantatie over aan iemand anders'. Wanneer een persoon niet geregistreerd staat bij overlijden, bepalen de partner of familie of hij donor is of niet.

\section{Resultaten}

In 2014 was $40 \%$ van de Nederlandse bevolking van 12 jaar en ouder geregistreerd in het Donorregister, en $24 \%$ geeft toestemming tot orgaandonatie. Deze gegevens zijn gekoppeld aan de gegevens die in de EBB in de periode 2010-2014 zijn verzameld, inclusief de informatie over religie. Na een selectie van de personen die hebben meegedaan aan de EBB neemt de proportie die geregistreerd is toe naar $45 \%$ van de Nederlandse bevolking van 15 jaar of ouder. Van deze groep heeft $29 \%$ toestemming gegeven voor orgaandonatie, van wie $6 \%$ bepaalde organen of weefsels van donatie uitsluit. Verder heeft $11 \%$ expliciet geen toestemming gegeven, en $6 \%$ laat deze beslissing over aan nabestaanden of een aangewezen persoon. De rest - 55\% - heeft zich niet geregistreerd.

11 Nederlandse Transplantatie Stichting, 'Ontwikkelingen in wachtlijst, donatie en transplantatie', in: S. de Groot e.a. (red.), Jaarverslag 2015: samen sterker, Leiden 2015, p. 8-21. 
Tabel 1 Ingeschreven als orgaandonor naar denominatie en bijwonen religieuze diensten, 2014

\begin{tabular}{lll}
\hline & & $\%$ \\
Denominatie & Geen & 34,6 \\
& Rooms-katholiek & 28,8 \\
& Nederlands-hervormd & 21,8 \\
& Gereformeerd & 21,7 \\
& PKN & 27,1 \\
& Islam & 1,3 \\
Bijwonen religieuze diensten & Andere gezindte & 16,7 \\
& Zelden of (vrijwel) nooit & 30,9 \\
& Minder dan I keer per maand & 26,9 \\
& I keer per maand & 24,8 \\
& 2 tot 3 keer per maand & 24,5 \\
N = 38I.477 & Minstens I keer per week & 16,1 \\
\hline
\end{tabular}

Bron: CBS

Bekend is dat ook andere bevolkingskenmerken gerelateerd zijn aan orgaandonatie. ${ }^{12}$ Onder vrouwen, middelbare leeftijdsgroepen, hoogopgeleiden en autochtonen is de proportie geregistreerde orgaandonoren groter dan onder mannen, jongeren en ouderen, laagopgeleiden en (vooral niet-westerse) allochtonen. Ook is er een verband met de arbeidsmarktpositie. Vooral personen die actief zijn op de arbeidsmarkt hebben zich geregistreerd en geven toestemming tot orgaan- en weefseltransplantatie. Daarnaast is inkomen onderscheidend: personen met een hoger inkomen staan vaker geregistreerd en zijn vaker donor.

Maar ook religie doet er toe (zie tabel 1). Met 35\% vinden we de meeste donoren onder de onkerkelijken. Bovendien zijn er grote verschillen tussen denominaties. Onder de rooms-katholieken bevindt zich het grootste aandeel donoren (29\%), gevolgd door de PKN'ers (27\%), gereformeerden en Nederlands-hervormden (22\%), terwijl nauwelijks moslims (1\%) toestemming geven om hun organen te gebruiken. De mate waarin het geloof wordt beoefend door het bijwonen van religieuze diensten is ook onderscheidend. Vooral de zeer frequente bezoekers, die minstens één keer per week een dienst bijwonen, zijn minder vaak geregistreerd als donor (16\%). De groepen die minder vaak naar een gebedshuis gaan, onderscheiden zich veel minder in de proportie orgaandonoren; dat varieert van 25 tot $31 \%$.

12 F. Peters \& H. Schmeets, 'Het donorregister: wie doet mee en wie niet?', Bevolkingstrends 2015, 2, p. 1-9. 
De religieuze groepen en de niet-religieuzen verschillen sterk in samenstelling naar kenmerken die onder andere voor orgaandonatie relevant zijn, zoals leeftijdsopbouw, man-vrouwverdeling, opleidingsniveau, besteedbaar inkomen en herkomst. Maar ook als we hiermee rekening houden, blijven de verschillen in de aandelen orgaandonoren in belangrijke mate voorhanden. Ook dan blijkt dat onkerkelijken de grootste kans hebben om zich als orgaandonor in te schrijven. Ze worden daarin gevolgd door de rooms-katholieken en vlak daarna de PKN'ers. De twee andere protestantse groepen, de gereformeerden en hervormden, hebben al beduidend lagere porties orgaandonoren, maar veruit het kleinste aandeel is te vinden onder de moslims. Dus de samenstelling van de religieuze groepen betreffende de vermelde bevolkingskenmerken die op zich gerelateerd zijn aan orgaandonatie, biedt maar zeer ten dele een verklaring voor deze verschillen. De denominatie blijft onderscheidend. Ook blijft na correctie het onderscheid voorhanden tussen de personen die zeer frequent naar een gebedshuis gaan ten opzichte van groepen die dat minder vaak doen.

Op basis van deze bevindingen kunnen we concluderen dat de relatie tussen de religieuze groepen en orgaandonatie slechts gedeeltelijk overeenstemt met onze verwachtingen. De verwachting dat het lidmaatschap van een religieuze gemeenschap de kans verhoogt om zich als orgaandonor te registreren, is niet terug te vinden in de resultaten. Het is duidelijk dat andere onderliggende mechanismen een rol spelen, zoals institutionele of levensbeschouwelijke bezwaren die inherent zijn aan bepaalde religieuze overtuigingen. ${ }^{13}$ De heiligheid van het lichaam kan worden ervaren als een belangrijk obstakel om zich als orgaandonor in te schrijven. Denkbaar is dat dergelijke bezwaren zwaarder wegen dan, vanuit de sociaalkapitaalgedachte, solidariteit en wederzijdse steun. Blijkbaar is er geen sprake van een vertaalslag van de sterkere participatie en vertrouwen bij bepaalde religieuze groepen in een groter aandeel dat zich als donor heeft geregistreerd. Bovendien kunnen religieuze regels, praktijken en overtuigingen verschillen tussen denominaties verklaren. Zo bespreekt en ondersteunt de rooms-katholieke kerk orgaandonatie, terwijl de protestantse kerken de verantwoordelijkheid en beslissing meer expliciet leggen bij het individu. ${ }^{14} \mathrm{Bij}$ de islamitische leer is de wijze hoe men dient om te gaan met orgaandonatie afhankelijk van de interpretatie van de religieuze vertegenwoordigers en de rol van overheidsfunctionarissen bij het informeren en motiveren van mensen om zich als orgaandonor te registreren. ${ }^{15}$ Of dit ook toepasbaar is op de situatie in Nederland, is echter niet duidelijk. Mogelijk speelt er in Nederland onder de moslims tevens een andere dynamiek bij orgaan-

13 A. Alam, 'Public opinion on organ donation in Saudi Arabia', Saudi Journal of Kidney Disease and Transplantation 2007, 18, p. 54-59; M. Tarhan e.a., 'The View of Religious Officials on Organ Donation and Transplantation in the Zeytinburnu District of Istanbul', Journal of Religious Health 2015, 54, p. 1975-1985.

14 J. Sanders, Leven door geven: religieuze en levensbeschouwelijke standpunten over orgaan- en weefseldonatie, Zoetermeer 2003.

15 G. Randhawa e.a., 'Religion and Organ Donation: The Views of UK Faith Leaders', Journal of Religious Health 2012, 51, p. 743-751; E. Güden, F. Cetinkaya \& M. Naçar, 'Attitudes and Behaviors Regarding Organ Donation: a Study on Officials of Religion in Turkey', Journal of Religious Health 2013, 52, p. 439-449. 
donatie dan in de herkomstlanden. Moslims kunnen zich buitengesloten voelen, bijvoorbeeld door een geringe toegang tot de arbeidsmarkt, waardoor ze minder bereid zijn om iets voor de samenleving te willen doen. ${ }^{16}$ Binnen het boeddhisme en hindoeïsme (vertegenwoordigd in de categorie 'andere gezindte' vanwege hun geringe omvang in Nederland) wordt orgaandonatie soms opgevat als potentieel schadelijk voor de ziel in het kader van reïncarnatie voor zowel het geven als het ontvangen van organen. Het negatieve verband tussen het veelvuldig bijwonen van religieuze diensten en orgaandonatie biedt aanvullende inzichten voor de posities die de denominaties innemen, aangezien de gemiddelde frequentie van kerkbezoek verschilt tussen religieuze groepen.

We vervolgen nu de analyses door de besproken relaties te specificeren naar leeftijd. De keuze om deel uit te maken van een bepaalde levensbeschouwelijke groepering heeft onder ouderen veelal veel eerder plaatsgevonden dan bij jongeren. Daarbij geldt ook dat het vroeger veel meer een automatisme was, door sociale conventie, dan een bewuste, persoonlijke keuze. Vanuit deze redenering is te verwachten dat de relatie tussen religie en orgaandonatie sterker zal zijn onder jongeren dan onder ouderen. We hanteren een onderscheid tussen jongeren (15 tot 40 jaar) en ouderen (40 jaar of ouder). De kans dat iemand zich als orgaandonor heeft geregistreerd, is groter onder de niet-religieuze groep dan onder de groeperingen die wel behoren tot een religie. De discrepantie tussen rooms-katholieken en niet-religieuzen is, conform deze verwachting, groter onder jongeren dan onder ouderen (zie tabel 2). De rooms-katholieke jongeren hebben $26 \%$ minder kans (Odds ratio $=0,74$ ) om donor te zijn dan ouderen, waar de kans slechts $11 \%$ minder is (Odds ratio $=0,89$ ). Dit patroon is echter omgekeerd voor protestanten. Nederlands-hervormden, gereformeerden en PKN'ers in de oudere leeftijdscategorie zijn minder vaak orgaandonor ten opzichte van de niet-religieuzen dan de jongere leeftijdsgroep. Bij moslims is er nauwelijks verschil tussen jong en oud: de kans om orgaandonor te zijn is onder beide leeftijdsgroepen uiterst gering.

De divergerende effecten bij de twee leeftijdsgroepen heeft ook gevolgen voor de discrepantie tussen rooms-katholieken en protestanten: vooral onder de oudere generatie zijn katholieken veel meer bereid om hun organen ter beschikking te stellen dan protestanten, terwijl er slechts geringe verschillen zijn onder de jongeren.

Ook verschilt de relevantie van het bijwonen van religieuze diensten tussen beide leeftijdsgroepen. Het frequent bijwonen van religieuze diensten heeft voor zowel jong als oud een negatief effect op orgaandonatie. De discrepantie in orgaandonatie tussen individuen die minstens één keer per week religieuze diensten bijwonen en degenen die minder vaak gebedshuizen bezoeken, is echter iets kleiner voor de 40-plussers. 


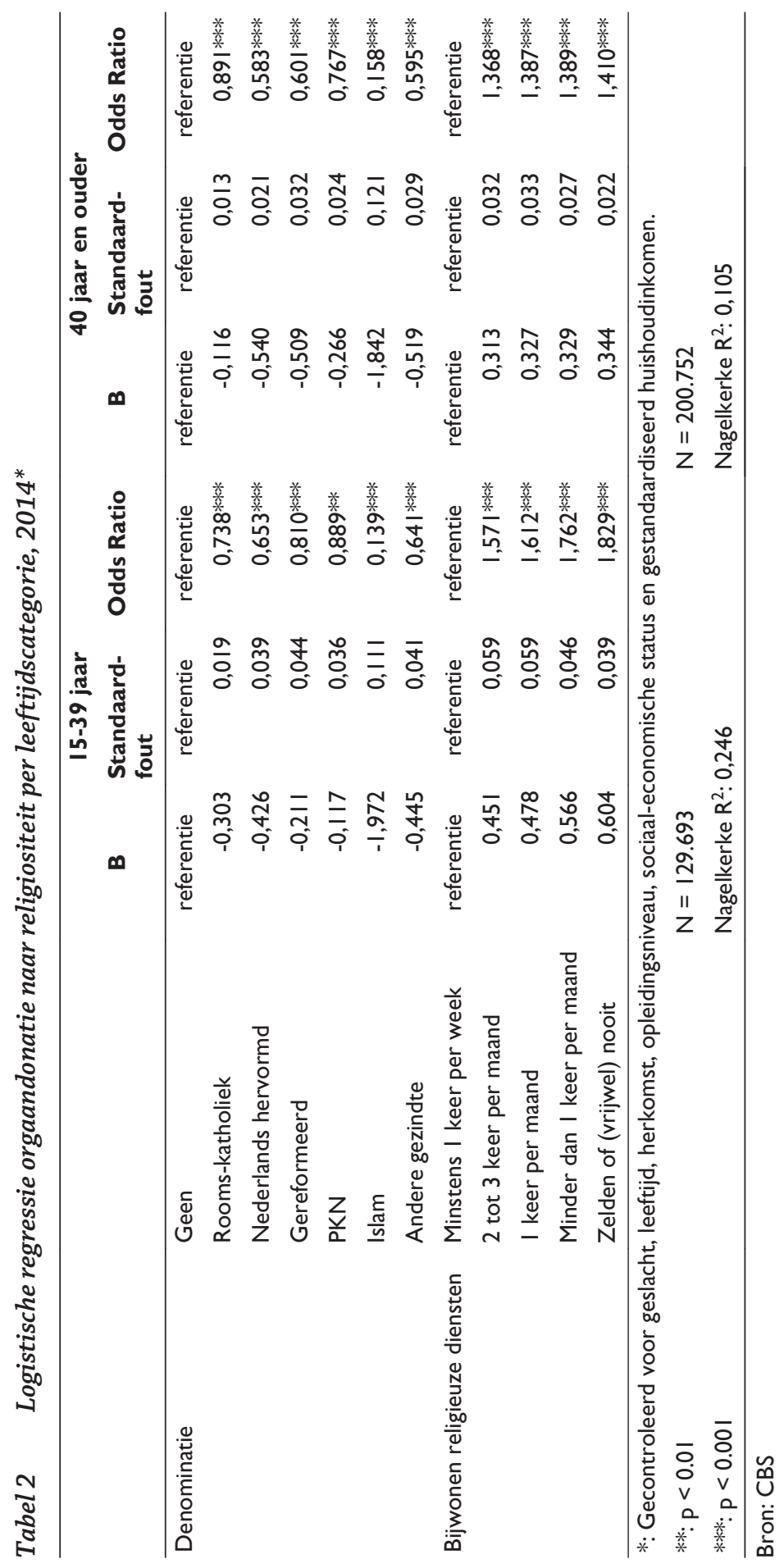


De divergerende werking van denominatie en het praktiseren van het geloof in gebedshuizen op orgaandonatie tussen de jonge en oude generatie roept de vraag op in welke mate de denominaties zich onderscheiden in het bezoek aan religieuze diensten. Bij de katholieken zien we een sterke kloof: van de 15- tot 39jarigen gaat slechts $8 \%$ nog regelmatig naar de kerk, terwijl dat onder de 40-plussers met $22 \%$ bijna drie keer zo hoog is. Bij de protestanten ziet dit beeld er heel anders uit. Zowel jong als oud gaat veel vaker naar een kerkdienst. Onder de Nederlands-hervormden is dit respectievelijk 35 en 27\%, onder gereformeerden 70 en $60 \%$, en onder de PKN'ers 55 en $62 \%$. Ook indien we kijken naar de proporties die minstens één keer per week naar de kerk gaan, zien we dergelijke verschillen tussen jong en oud tussen de denominaties. Dit betekent dus dat de invloed van de kerkdienst op het registreren als orgaandonor nauwelijks een rol kan spelen voor de katholieke jongeren en voor een beperkt deel van de katholieke ouderen. Bij de protestanten kan deze invloed wel substantieel zijn, zowel voor jongeren als voor ouderen, en dan vooral voor de gereformeerden en PKN'ers. Als we nu veronderstellen dat het bijwonen van religieuze diensten voor katholieken en protestanten een dempend effect heeft op orgaandonatie, dan zouden we dit vooral moeten zien bij protestanten, en meer specifiek bij de hervormden en gereformeerden iets meer onder de jongeren, en bij de PKN'ers iets meer bij de ouderen. Bij katholieken zou dit dus, hoewel beperkt, sterker moeten spelen bij de ouderen. De effecten in tabel 2 stroken hier echter niet mee. Immers, de kans om zich als orgaandonor te registreren is groter onder katholieke ouderen, en kleiner onder hervormde en gereformeerde ouderen. Wel is de geringere kans onder de oudere PKN'ers te duiden door de, hoewel bescheiden, grotere deelname aan religieuze diensten.

Deze resultaten zijn verrassend en suggereren dat het effect van het praktiseren van religieuze diensten anders uitpakt voor de verschillende denominaties. Om daar meer zicht op te krijgen zijn in tabel 3 de resultaten opgenomen van de afzonderlijke analyses voor personen die minstens één keer per maand religieuze diensten bijwonen, en degenen die dat niet doen. De rooms-katholieken zijn de referentiecategorie. Daaruit blijkt dat onder de regelmatig praktiserende gelovigen de verschillen tussen de katholieken en andere geloofsgroepen groter zijn dan onder de gelovigen die minder vaak naar een religieuze dienst gaan. Daarbij geldt dat het verschil tussen de praktiserende katholieken en protestanten vooral zichtbaar is onder de gereformeerden en Nederlands-hervormden, en in minder mate bij de PKN'ers. Het onderscheid met de moslims blijft nagenoeg ongewijzigd. Dit geeft dus aan dat het naar de kerk gaan wel degelijk een extra impact heeft, maar bovendien zorgt voor een toename van het verschil tussen katholieken en protestanten. Dit suggereert dat de katholieke dienst een ander effect sorteert dan de protestantse kerkdiensten, waarbij het negatieve effect van kerkdiensten op orgaandonatie beperkter is onder katholieken dan onder protestanten. Met vervolgonderzoek, zoals bij priesters en dominees, zou meer zicht op dergelijke invloeden van gebedsdiensten verkregen kunnen worden. 


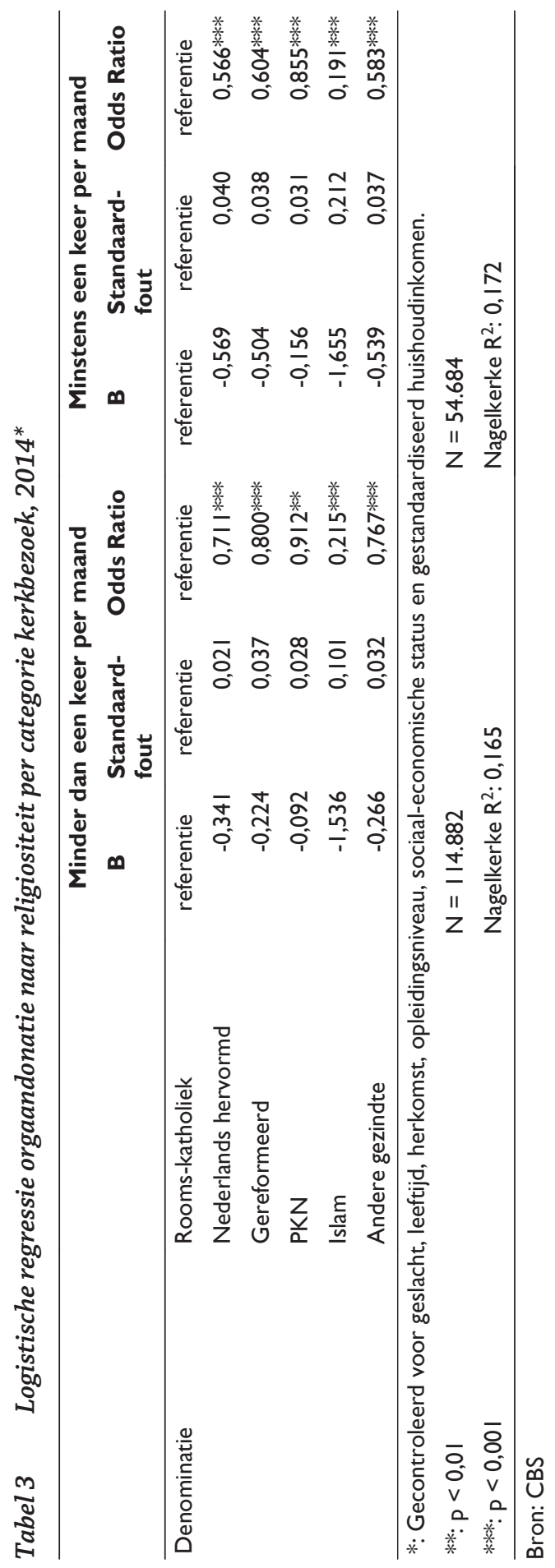




\section{Conclusie en discussie}

In dit artikel is de relatie tussen religiositeit en donorregistratie onderzocht met behulp van unieke registergegevens van het CBS. Verwachtingen omtrent deze relatie zijn gebaseerd op bevindingen ontleend aan onderzoek naar sociale cohesie. De bereidheid om je organen te doneren kan worden opgevat als een bijzondere vorm van liefdadigheid. Het belangrijkste verschil ten opzichte van geefgedrag, in de vorm van bijvoorbeeld schenkingen en giften, ${ }^{17}$ is dat de begunstigde onbekend is. In dit opzicht is het ter beschikking stellen van de organen een daad van naastenliefde en impliceert het een verbondenheid met de samenleving. Aangezien religieuze mensen meer vertrouwen en participatie in de samenleving etaleren, was onze verwachting dat religieus betrokken personen zich vaker laten registreren als orgaandonor. Vanuit dit perspectief zouden we tevens verwachten dat vooral protestanten orgaandonor zouden zijn, terwijl de proportie donoren onder moslims veel kleiner zou zijn.

De resultaten laten echter zien dat mensen die behoren tot een religieuze of levensbeschouwelijke groepering minder geneigd zijn om hun organen ter beschikking te stellen dan de niet-religieuzen. Verder zijn er grote verschillen tussen de denominaties: rooms-katholieken hebben meer kans om te doneren dan protestanten, maar dat geldt vooral voor degenen die zeggen gereformeerd of Nederlands-hervormd te zijn, en veel minder voor de PKN'ers. Wel strookt het lagere aandeel donoren onder de moslims met onze verwachtingen.

Daarnaast, en eveneens in tegenstelling tot onze verwachtingen, vonden we een negatieve relatie tussen het bijwonen van religieuze diensten en het percentage orgaandonoren. Daarbij ligt het onderscheid tussen de groep die gemiddeld minimaal één keer per week een gebedshuis bezoekt, en de groepen die dat minder vaak doen. Hoewel de mechanismen die ten grondslag liggen aan deze resultaten verder specifiek onderzoek vereisen, veronderstellen we dat institutionele belemmeringen die inherent zijn aan de religieuze leer sterker zijn dan het meedoen met en het vertrouwen hebben in de samenleving. Elke religie heeft haar eigen standpunten over orgaandonatie, die een deel van de verschillen tussen denominaties kunnen verklaren. Echter, geen enkele religie verwerpt officieel orgaandonatie. ${ }^{18}$ Dus de (negatieve) houding moet worden verklaard door andere mechanismen.

Onderzoek uit Turkije toont aan dat een van de belemmeringen voor orgaandonatie en -transplantatie te wijten is aan het al dan niet leveren van correcte informatie door de geestelijke leiders en ambtenaren aan het publiek. ${ }^{19}$ Het algemene gevoel onder het Turkse volk zou zijn dat orgaantransplantatie door de religie wordt verworpen, met als gevolg dat een grote meerderheid tegen orgaandonatie

17 R. Bekkers, T. Schuyt \& B. Gouwenberg (red.), Geven in Nederland 2015. Giften, Nalatenschappen, Sponsoring en Vrijwilligerswerk, Amsterdam 2015.

18 P. Bruzzone, 'Religious aspects of organ transplantation', Transplantation Proceedings 2008, 40, p. 1064-1067.

19 Tarhan e.a. 2015, p. 1975-1985. 
is. ${ }^{20}$ In Nederland wonen bijna 400.000 Turkse migranten (eerste en tweede generatie) en zij vormen - samen met de migranten uit Marokko en Suriname - de grootste herkomstgroep. Een overgrote meerderheid van de migranten uit Turkije zijn moslim en dat zou kunnen verklaren waarom slechts een zeer klein deel toestemming geeft om hun organen te gebruiken nadat ze zijn overleden. We hebben geen aanwijzingen of dit ook een verklaring kan bieden voor bijvoorbeeld Marokkanen, die ook overwegend moslim zijn.

Hoewel de verschillen in orgaandonatie tussen de andere denominaties veel geringer zijn, vinden we een groter aandeel orgaandonoren onder rooms-katholieken in vergelijking met de drie onderscheiden protestantse denominaties, waaronder vooral de Nederlands-hervormden of gereformeerden en in iets mindere mate bij de PKN'ers. Verder blijkt dat dit verschil in orgaandonatie tussen katholieken en protestanten vooral geldt voor de 40-plussers, en veel minder voor de 15- tot 39-jarigen. Bovendien is het verschil tussen katholieken en protestanten groter onder degenen die regelmatig naar een gebedshuis gaan dan onder de minder praktiserende gelovigen.

De logische vervolgvraag is waarom oudere en praktiserende katholieken zich zo sterk onderscheiden ten opzichte van protestanten in het inschrijven als orgaandonor. Dit is lastig te beantwoorden. Mogelijk dat de katholieke leer met een duidelijk standpunt over orgaandonatie, uitgedragen tijdens de gebedsdiensten, hierbij een rol speelt, terwijl in de protestantse kerken dit aan het individu wordt overgelaten. ${ }^{21}$ Een andere, aanvullende, verklaring is dat jonge katholieken doorgaans nog maar zelden naar een kerkdienst gaan en dat daardoor de invloed van de priester nauwelijks nog een rol kan spelen, terwijl dat voor oudere katholieken nog wel het geval is.

Religie biedt zodoende een, hoewel complex, handvat om de verschillen in orgaandonatie te kunnen duiden. Wat kunnen we verwachten voor de toekomst? De Wetenschappelijke Raad voor het Regeringsbeleid (WRR) heeft zich gebogen over alternatieven voor het huidige 'nee, tenzij'-systeem, zoals het opt-out- of forced-choicesysteem. In een opt-outsysteem is iedereen donor, tenzij een persoon aangeeft dat niet te willen. In een forced-choicesysteem wordt onder bepaalde omstandigheden, bijvoorbeeld bij het behalen van het rijbewijs, als voorwaarde gesteld dat men een keuze maakt al dan niet donor te worden. Dat zal waarschijnlijk het aantal orgaandonoren fors doen toenemen. De WRR maakt geen duidelijke keuze, maar stelt vooral richtingen voor die een alternatief zijn voor het huidige systeem. ${ }^{22}$ Een van die richtingen is uitgewerkt in een wetsvoorstel van D66. Dit voorstel is op 13 september 2016 met een krappe meerderheid goedgekeurd door de Tweede Kamer. Dit voorstel lijkt sterk op het opt-out systeem, met dien

20 M. Akiş e.a., 'Knowledge and attitudes of Süleyman Demirel University's staff towards organ donation and transplantation', Journal of the Süleyman Demirel University Faculty of Medicine 2008, 15, p. 28-33; A. Őzer e.a., 'Knowledge, atitudes and behaviors of officials of religion about organ donation in Kahramanmaras, an Eastern Mediterranean city of Turkey', Transplantation Proceedings 2010, 42, p. 3363-3367.

21 Sanders 2003.

22 Wetenschappelijke Raad voor het Regeringsbeleid, Met kennis van gedrag beleid maken. Amsterdam, 2014. 
verstande dat er een mogelijkheid is dat de nabestaanden, indien ze aannemelijk kunnen maken dat de overledene echt geen donor had willen zijn, dit alsnog kunnen voorkomen. Het voorstel moet wel nog door de Eerste Kamer worden goedgekeurd. Mocht het voorstel alsnog door de senaat afgewezen worden, dan is het aannemelijk dat de toename van het aantal orgaandonoren veel langzamer zal groeien, waarbij de afname van religieuze betrokkenheid een impuls kan geven aan de bereidheid om organen ter beschikking te stellen aan anderen. 